\title{
What is Narrative Possibility?
}

\section{Introduction}

There's been a recent uptick in interest in the notion that some scientific explanations have the form of a "narrative" (see Currie 2019; Roth 2020; Beatty 2017 for a handful of examples). In theorizing about the applications of narrative explanations, a number of interesting questions emerge. We might ask, for instance, "What is a narrative," or, "How do narratives explain?" Indeed, this is where most of the philosophical action has been, up to now. In recent work, John Beatty (2016) and Derek Turner and Marc Ereshefsky (2020) have tried to answer another interesting question: "What are narrative explanations good for?"

One answer to the question of what narratives are good for, according to some authors, is that they assist us in making sense of possibilities (Beatty 2016; 2017). This is to say that a good explanation, in narrative form, should in some sense illuminate the modal space that narrative explanations inhabit. ${ }^{1}$ There are, however, some deep disagreements concerning what the appropriate notion of narrative possibility really is, and how narrative explanations connect to the modal spaces that these explanations are meant to cover. I think there are basically two approaches represented in the literature up to now. One approach I term metaphysical, and the other epistemological (I'll explain what these are below). Each approach, I argue, provides some crucial insights for

\footnotetext{
1 "Modal space" is meant to denote something rather metaphysically minimal here. An anonymous reviewer has noted that there are many ways in which philosophers speak of modality: logical possibility, metaphysical possibility, physical possibility, and (perhaps more controversially) biological possibility. I don't see narrative possibility as mapping neatly onto any of these more well-known conceptions of modality. Narrative possibility, contextual as it turns out to be, might then mark out a separate subspace of modality, marked specifically by its use of central subjects, etc. (which will be explained later) as the determinants of the relevant modal space.
} 
thinking about the nature of narrative possibility, but have some shortcomings as concerns what I take as the primary task of an appropriate concept of narrative possibility: namely, delimiting and illuminating an explanatory modal space.

In what's to come, I'll argue for an ecological conception of narrative possibility that serves just this purpose. This account explicates the concept of narrative possibility in terms of a relation between the capacities of a narrative subject and the affordances of its narrative context. I'll argue that this account captures the most appealing aspects of the metaphysical and epistemological approaches, and that it succeeds at delimiting the modal spaces underlying narrative explanations, whereas other accounts do not.

\section{Narrative explanation: an operative definition}

A quick note concerning the notion of narrative explanation itself is in order. The concept of narrative explanation has been given many treatments. Some take it to be a form of "reasons" explanation (e.g. Dray 1957); others have it that narratives are sometimes (or always) forms of mechanistic explanation (see Glennan 2010; Currie 2014; Swaim 2019); others take narrative to explain in terms of description of causal (and perhaps non-causal) event sequences (see Roth 2019; Richards 1992).

I'm broadly sympathetic to the mechanistic approach, which is to say that on my view, narrative explanations should situate the subject of the narrative within a network of causal-mechanistic relations, and work to draw explanatory lessons from these networks. The point of this paper, however, is not really to defend this or that conception of narrative explanation specifically, but instead to advance a conception of 
narrative possibility that can do work within the context of broader theorizing about narrative explanation. With that said, I think it best to offer an ecumenical conception of narrative explanation that assumes very little concerning philosophical commitments to any particular account. To begin with, I'll offer the following, decidedly minimal, definition of a narrative:

A narrative is a temporally extended sequence of events, involving a central subject, bound together by some kind of relation.

I grant that this isn't especially illuminating, but this is because I want the reader not to be distracted by debates of the nature of narrative explanation itself, which, as I say, is somewhat removed from the goals of this article. While I take this definition to be rather ecumenical, there is one substantive assumption in this stipulative definition of narrative worth noting: it takes narratives to be things that are a part of the world. That is, narratives are things that are discovered, not merely constructed (see Dray 1961 for a sympathetic take; see Roth 2020 for an opposing take). ${ }^{2}$ Whether or not this is in fact the case is not something that I'll argue for directly, but it does map to my previous comments about narratives (at least in the natural sciences and the like) as primarily mechanistic. But perhaps these worries can be somewhat offset by offering the following (stipulative) definition of narrative explanation:

\footnotetext{
${ }^{2}$ The most obvious exception to this, perhaps, is literary narratives. I grant that some narratives are harder than others to fit into this seemingly ontic framework, but I think there's a sense in which even literary narratives have an ontic element. Literary narratives, for instance, try to illuminate parts of the human condition through the use of fictional characters. The fictional characters, then, can be said to be something like fictional "models" of things that are very much a part of the world; namely, us.
} 
A narrative explanation involves a temporally extended sequence of events, involving a central subject, bound together by some kind of relation, and by virtue of that relation, is apt to be recounted in such a way as to provide explanatory understanding.

This may, I hope, ameliorate some of the concerns as regards the nature of narrative itself, as given in the minimal definition of a narrative. When we move from our stipulative definition of narrative to our stipulative definition of narrative explanation, we're granted some wiggle room as to what kinds of things ultimately make explanations explanatory or illuminating, which is certainly the more philosophically interesting question. ${ }^{3}$ In any case, I take it that the kind of relation that is going to be of interest will be one that relates the central subjects of narrative explanations and affordances given by their narrative environment in the appropriate way. Central subjects are spatiotemporally continuous entities (or perhaps processes) ${ }^{4}$ around which narratives are woven (persons, organisms, populations, genes, etc.). Affordances are just those background features of the central subject's environment that render a narrative pathway either open or closed. I will have much more to say about this in what's to come.

\footnotetext{
${ }^{3}$ The relation doing explanatory work may be of an ontic sort, or it may be primarily epistemic, for instance. There is room for variation. How this is so will become clearer later on in the paper.

${ }^{4}$ I simply flag here that I assume no ontology; entities, processes, etc. may be taken as ontologically fundamental, and I stake no claim as to which ontology is the right one.
} 


\section{Outlining extant approaches}

In this section I'll take a closer look at the views on narrative possibility that are most prominent in the literature up to now - the metaphysical and epistemological approaches. First, I'll discuss the metaphysical approach, most forcefully defended by John Beatty and Eric Desjardins (Beatty 2017; Beatty 2017; Desjardins 2011; Beatty and Desjardins 2009). The key insight of the metaphysical approach, I'll argue, is that theories of narrative explanation need to resist the trivialization of the notion of possibility (an idea which I'll explain shortly). Then I'll turn my attention to the epistemological approach, as defended by Derek Turner and Marc Ereshefsky (Turner 2007; Ereshefsky and Turner 2020). Their key insight is that we should resist metaphysical overextension when theorizing the role of possibility in narrative explanations.

\subsection{The metaphysical approach}

Recall our motivating question: "What are narratives good for?" We said that one answer to that question is that narratives should do some work toward helping us make sense of possibilities. This isn't a new insight. W.B. Gallie (1964) argues, for instance, that what narrative explanations do (in part) is they situate our understanding of narrative outcomes relative to salient "turning points" in a narrative sequence. Turning points are something like crucial events, but they're also more than that. Turning points are locations within a narrative structure where the force of the narrative seems to push events along one trajectory, even though it strikes us as entirely possible that things 
might have gone some other way (Gallie 1964; 1955; Beatty 2016). We're able to see how it is that what happened hinged upon (or was "contingent upon") some crucial events in the past causal history of the narrative (see Beatty 2006; Gould 1989).

This notion of turning points, then, allows us to speak in terms of the contingency of events. Further, following S.J. Gould (1989) and John Beatty and Eric Desjardins (2009) we can distinguish between two kinds of contingency: contingency upon (already mentioned above) and contingency per se..$^{5}$ As we've seen, possibility in the sense of contingency upon just means that some later event is possible only by dint of some earlier event's occurrence. Evolutionary narratives, for instance, often involve contingency upon, since giving an account of the emergence of some adaptive trait will involve accounting for the features of populations, organisms, and selective regimes that made its emergence possible. Contingency per se is something stronger than this. The per se conception of contingency is committed to something like "genuine openness" - that is, this stronger sense of contingency holds that there really are alternate histories that might have occurred, even though they didn't.

The weaker notion (contingency upon) is fairly uncontroversial - the popularity of counterfactual theories of causal explanation (e.g. Lewis 1973; Woodward 2003) attests to this fact. This notion of possibility, though, might strike some as relatively thin (at least in certain contexts). Beatty and Desjardins (Beatty 2016; Beatty 2017; Beatty and Desjardins 2009) argue forcefully that the proper way to think about narrative

\footnotetext{
${ }^{5}$ For more helpful discussion on contingency (and especially its role in evolutionary theory) I direct the reader to Beatty (1993) for a thorough (and canonical) treatment. It's also worth noting that Beatty and Desjardins (2009) point helpfully to a potential confusion in Gould (1989), which is that he sometimes also slips into talking about contingency as something like "sensitivity to initial conditions," without really registering the fact that this sense of contingency is different and distinct from the others.
} 
possibility is in terms of contingency per se. This is to say that according to their view, narrative possibility involves a commitment to the reality of unrealized historical outcomes as a part of the world's real structure (Beatty 2017).

This brings us back to Gallie's (1964) notion of turning points. Narrative turning points, recall, are events within a narrative sequence where the narrative breaks in one direction, while it seems it need not have done so. That is, things could have gone some other way (i.e. some other outcome was possible). On the metaphysical view, we should read this as a literal part of the world's structure. There really are, according to the metaphysical view, other ways that the world could have been. Indeed, if this weren't the case, narrative explanation would not even be a worthwhile endeavor (Beatty 2016;).

According to this view, narratives explain, at least in part, by making reference to unrealized outcomes (Beatty 2017). Stated another way, the significance of narrative outcomes can be seen only by contextualizing them in terms of other possible outcomes that weren't realized. Beatty (2016) uses "regret narratives" as paradigm examples of this core insight. Regret narratives are just what they sound like-reflections on the part of some central character with respect to some set of decisions that they regret having made for some reason or another (think of It's a Wonderful Life, for instance). In such narratives, the significance of what has happened to the narrative subject can be made sense of only by referencing or alluding to some alternate circumstances. That is, while the world turned out to be one way, the subject sees that it could have been another, if only she'd made a different decision at some crucial juncture. 
A similar kind of reasoning might apply to natural historical narratives. Explaining the emergence of some novel biological trait can only be done, on this view, by situating what happened (the emergence of bipedal locomotion in hominins, say) in terms of other evolutionary outcomes that failed to obtain (even though they might have). The explanation surely involves some crucial turning points: ${ }^{6}$ the emergence of certain selective regimes, the break-off of some founder population of early primates, the occurrence of some fortuitous mutations, etc. But crucially, according to the metaphysical view, there was never any point at which the realized outcome was determined or necessitated. The unrealized possibilities are real possibilities, and if that weren't true, it wouldn't make any sense to offer explanations in narrative form.

Narrative explanations, recall, are supposed to be especially suited to the task of making sense of possibility. This is what narratives are supposed to be "good for" (Beatty 2016). If possibility weren't baked into the structure of the world, then narrative explanations would be effectively reducible to something like Deductive-Nomological explanations (Hempel and Oppenheim 1948). ${ }^{7}$ In a deterministic world, they argue, nothing would be worth narrating, and narrative forms of explanation would have no real purchase. The high degree of contingency and stochasticity in biological and evolutionary phenomena, however, seems to lend credence to the idea that the world supports narrative explanations in at least some contexts (Beatty 2006; Beatty 2017;

\footnotetext{
${ }^{6}$ While it's common to think about narratives as involving "turning points" it has lately been recognized by some (Currie correspondence; Turner correspondence) that some narratives may be narratives of stasis. Perhaps evolutionary equilibria of various sorts may be the subjects of narrative explanations, for instance. This strikes me as plausible, but I have nothing to say about such narratives here. ${ }^{7}$ See also Hempel (1942). There he explicitly argues that historical explanations are typically just "explanatory sketches" that, if filled out, would have the form of DN explanations. The problem is just that we don't typically have the information to do the labor of "filling out."
} 
Millstein 2000; Gould 1989). Insofar as that's the case, it must be that the world's structure itself is the kind of thing that is narratable. According to the metaphysical view, narrative explanations are effective because possibility is baked into the structure of the world.

\subsection{The epistemological approach}

The epistemological approach to narrative possibility tends to emphasize the role of evidential underdetermination (Turner 2007; Ereshefsky and Turner 2020). ${ }^{8}$ That is, the epistemological approach holds that the reason we speak about possibility in narrative contexts at all is because several historical sequences appear compatible with our evidential situation. "Possibility" refers to a certain state of affairs concerning our knowledge situation, not necessarily a special set of facts about the structure of the world (as the metaphysical approach would have it). ${ }^{9}$

The idea here is relatively straightforward. In order to explain some historical phenomenon, $p$, we need to construct a narrative sequence that properly accounts for it. In the case of natural history this presumably involves reconstructing a causal history, $h$, leading to $p$, such that $p$ is a consequence of the causal influences constituting $h$. One way of generating explanatory narratives like $h$ is to construct them from a set of

\footnotetext{
${ }^{8}$ Although I take it that the epistemological approach is informed in deep ways by problems of local underdetermination (as in Turner (2007)), this is not their sole concern by any means. They overlap in important ways with the explanatory concerns of metaphysical theorists - selection of central subjects, narrative trajectory, etc. There will likely be some disagreement over what makes some selection of a central subject, for example, "fit" for a particular explanatory task, but still, explanatory concerns overlap. ${ }^{9}$ It may be that the distinction here is not absolute. As mentioned elsewhere, we should ultimately think about these approaches as poles between which positions may vary. Whereas Ereshefsky and Turner (2020) count as having an epistemological view by my reading, they are less so than, for instance Roth (2020). The former are in some sense "tied to the world's structure," but certainly less so than Beatty and others.
} 
evidential traces, E (see Turner 2007, Cleland 2011). Underdetermination, however, rears its head rather quickly. For any $p$ and its attendant traces $E$, we can generate an equally well supported but strictly incompatible explanatory narrative, $h^{\prime}$ (Turner 2007; Swaim 2019). ${ }^{10}$ So, given some evidential traces, we have a set of possible explanatory narratives to choose from.

What this demonstrates, according to the epistemological conception of possibility, is that narrative forms of explanation can be useful even if the world is deterministic (Ereshefsky and Turner 2020; Swaim 2019). This runs counter to the claim advanced by the metaphysical theorists, who hold that some form of openness in the world is essential to the usefulness of narrative explanation. ${ }^{11}$ Their claim was that narrative explanations reduce to D-N explanations if the world lacks the openness they claim for it.

But considerations of underdetermination and the ways in which scientists negotiate these problems seems to show that the metaphysical theorists' worries are somewhat misplaced. Cleland (2011), for instance, argues that what historical scientists do is set out in search of "smoking guns" that can serve to break the tie between purportedly equivalent narratives. Dray (1951) argues that successful explanation turns

\footnotetext{
${ }^{10}$ This is not meant to be a strict definition of the epistemological position. Many weaker versions of the view are available and plausible on the epistemic approach. A proponent of the epistemological view might commit only to the claim that at some narrative turning point, although things went down narrative path A, for all we know, things might have just as easily gone down path B (I thank an anonymous reviewer for pointing this out). This stronger version that emphasises underdetermination, however, helps to highlight the stakes of the debate in a rather stark way, one which I think is helpful for expository purposes. I do not, however, bind the epistemological theorist to it.

${ }^{11}$ Beatty and Desjardins (2009) seem to think that "openness" is required in the strongest sense - that future states are not causally determined by previous states. I think it's possible (and preferable) to go for something weaker than this, where we might talk about probabilistic causation without making any commitments to indeterminacy (as in Strevens (2008, Ch. 10).
} 
on bringing historical events under their appropriate concepts. Adrian Currie (2019) argues that narratives perform a kind of "situating" function that allows us to see how the events to be explained stand in their proper historical relations to preceding ones. None of these explanatory strategies seem reducible to the D-N theory, and all of them seem perfectly consistent with our being in a fully deterministic world. So, the epistemological theorist claims, it is enough to talk about possibility in terms of our evidential situation, and any claims that extend our notion of possibility further are philosophically otiose.

\subsection{Some concluding thoughts and allusions to what's ahead}

On the face of things, I've constructed two categories of theorizing about narrative possibility: a metaphysical approach, and an epistemological one. More properly speaking, I've chosen representative examples of poles along a continuum of possible positions, the metaphysical pole being exemplified by the likes of Beatty and Desjardins (2009), and the epistemological pole being exemplified by Ereshefsky and Turner (2020). Given that our concept of narrative possibility should importantly inform our theories of narrative explanation, we want to be sure that the concept we advance can support our explanatory tasks in the appropriate ways (Currie correspondence). In some cases, narrative explanatory tasks may involve some degree of conceptual projection over an explanandum (see Roth 2019, Ch. 3). ${ }^{12}$ In other cases our explanatory

\footnotetext{
${ }^{12}$ Roth takes this notion of projection to hold in a very strong sense; historical events do not exist, on his view, until we've put them under our conceptual schemes. I do not share this view, especially in the strong sense argued by Roth. A lightly weaker version of this view can be found in Chapman and Wylie (2016).
} 
tasks might demand that we focus more intently on the concrete material structure of the world as we find it (e.g. Salmon 1989). While my sympathies will skew ultimately in the direction of respecting the concrete material structure of the world, it is still sensible to say that a good account of narrative possibility will respect some degree of explanatory pluralism, appropriately restricted.

In the next few sections I'll develop what I call an ecological conception of narrative possibility. The basic idea of this account is that narrative possibility should be viewed as a relation that holds between the capacities of a narrative subject and the affordances offered by the environment in which the narrative subject is situated. I'll show that by adopting this account, we can retain a solid commitment to a relatively robust notion of possibility as part of the structure of the world, while resisting the metaphysical overextension that worries the epistemological theorists. This account paves the way for good narrative explanations by delimiting the modal space that is properly representative of the concept of "narrative possibility." This delimiting function proves flexible enough to support a reasonable pluralism about narrative forms of explanation without being so flexible as to be devoid of philosophical content.

\section{Motivating the ecological account: Darwin and the Principle of Divergence}

In this section I'll give a broad outline of the ecological approach to narrative possibility, so as to illuminate its underlying motivation. As an example of something that outlines the kind of narrative possibility I'm pursuing, and its broader relation to narrative explanation, I'll turn to Charles Darwin and his "Principle of Divergence" as 
an instructive example. While many accounts of narrative explanation proper (which is to say, accounts of explanation rather than some aspect of it, such as narrative possibility) tend to focus more narrowly on concrete narrative subjects (i.e. concrete individuals), the rather abstract character of Darwin's Principle of Divergence allows us to see that the ecological conception of narrative possibility has wide application over many different classes of potential narrative subjects.

\subsection{Possibility, explanation, and Darwin's Principle of Divergence}

Darwin's Principle of Divergence (PD) is exemplary of the sort of ecological relation that my account of narrative possibility seeks to exploit. What, then, is PD? Darwin (1859) writes the following:

The principle, which I have designated by this term, is of high importance on my theory, and explains, as I believe, several important facts. In the first place, varieties, even strongly marked ones, though having somewhat the character of species-as is shown by the hopeless doubts in many cases how to rank them-yet certainly differ from each other far less than do good and distinct species. Nevertheless, according to my view, varieties are species in the process of formation, or are, as I have called them, incipient species.

Now what we want to know, according to Darwin (1859, p. 111), is how the relatively small differences between varieties can become "augmented" into the larger differences that prevail between proper species. There is, here, a kind of evolutionary imperative at play-populations must diversify. Mere varieties, being so close in physiological character, will have to compete with their parent species (or variety) for a broad range of resources, including food, habitat, and perhaps mating opportunities (see Pence and Swaim 2018, p. 444). So, according to PD, "[...] the more diversified the descendants 
from any one species become in structure, constitution, and habits, by so much will they be better enabled to seize upon the many and widely diversified places in the polity of nature, and so be enabled to increase in numbers" (Darwin 1859, p. 112, emphasis added).

How can we explicate Darwin's PD so as to shed some light on the notion of narrative possibility? It's interesting to note here that many of the biologists who have analyzed Darwin's PD have argued that it has no special explanatory power of its own within his theory of natural selection (see Mayr 1984). Divergence, it is argued, completely reduces to the effects of differential selection and reproduction. So, whereas Darwin took PD to be in some sense independent of the action of natural selection, in fact, natural selection (esp. competitive exclusion) alone can do all the necessary explanatory work.

I don't want to offer a knock-down argument against this interpretation of PD here, as that would take us a bit afield of the overall aim of this paper. That said, how one understands the explanatory value of PD will at least in part hinge on what one takes to be a good explanation for some set of biological phenomena. ${ }^{13}$ The reason Darwin understood PD as the "keystone" of his theory (Darwin 1859) is that he understands the aims of his theory as deeply ecological (Kohn 2009). What stands in need of explanation (at least in part) is the rich diversity of life, and how it comes to fill out the spaces in the "polity" or "economy" of nature in precisely the way it has. This being the case, the diverse structure of life's radiative bursts makes reference to both the

\footnotetext{
${ }^{13}$ I don't mean to be restricting my account of narrative to biological phenomena. Darwin's PD is being used as an expository tool to help in illuminating what this ecological account looks like, so for convenience, I'm speaking here in terms of biology.
} 
features of organisms and populations, and the background structure of nature. Organisms must have some set of features that allows them to move from one region of nature's economy into another, and nature must afford for the possibility of doing so (see Pearce 2009; Pence and Swaim 2018).

In relatively broad strokes, then, we can see what PD offers as a kind of window into the ecological view of narrative possibility I'm advancing. PD offers a thoroughly ecological view of how evolutionary change proceeds. The focus is on those features of organisms and populations which better enable them to diversify and radiate, but this is only possible if the environments in which they're embedded allow for those features to operate as a mechanism of action. But this kind of explanatory schema, with a structure of environmental affordances outlining what can be considered as broadly possible for a subject, can apply over a wide range of explanatory schemas. We need not speak in broad terms concerning radiative bursts and the like, but may instead, with equal justice, speak in terms of particular organisms, evolutionary lineages, or any other level of biological organization, so long as we can find a way to pick out a unit of analysis at that level of organization such that it can plausibly be thought of as the subject of a narrative. There is some reason to think that this ecumenicism about narrative subjects is plausible (see Glennan 2018, pp. 83-4).

\subsection{Wrapping up}

In this section I gave an example from the history of science to try to outline the basic shape of what an ecological account of narrative possibility might look like. Now 
I'll turn my attention to the nuts and bolts of the account. In the next two sections I'll offer an account of capacities and an account of affordances, as these are the two key elements of the conception of narrative possibility being advanced. After I've done this, I'll try to provide some synthetic comments concerning how these elements work together to provide a compelling and philosophically appealing account of narrative possibility.

\section{Central subjects and their capacities}

Part of the task of constructing a positive account of capacities is to give an account of those things which hold the relevant capacities in the first place. Ereshefsky and Turner (2020) argue that part of what's needed in philosophical treatments of historical and narrative explanation is to return to some of the work from the 1950s, 60s, and 70s - especially the work of people like David Hull (1975) and W.B. Gallie (1955; 1964). Their key contributions to discussions of narrative are the notions of "central subjects" (esp. Hull 1975), and "directionality" (esp. Gallie 1955). Both of these elements of narrative will figure in my account of narrative possibility, but I'll differ with Hull, Gallie, and Ereshefsky and Turner on some important particulars. I'll start by giving brief conceptual sketches of central subjects and narrative directionality as we receive them from Hull and Gallie. I'll then go on to offer a slightly different view that connects these concepts more closely with the relevant capacities of narrative subjects. 


\subsection{Central subjects}

What, then, are central subjects, and why are they important? According to Hull, "The role of the central subject is to form the main strand around which the historical narrative is woven" $(1975$, p. 255). Hull argues that the function of the central subject is to tell us what the narrative is about in the first place. Assuming that we can decompose the world atomistically along whatever lines we like, one immediate consequence is that the world is composed of a broad range of histories. By picking out a central subject, we get some traction on how to go about the task of constructing a narrative, as we now have a point of reference that can integrate the relevant facts in the appropriate way (Hull 1975; Ereshefsky and Turner 2020).

A question immediately arises: what kinds of things can be the central subjects of historical narratives? According to Hull, the most important feature of central subjects is that they are individuals. As individuals, central subjects provide for the basic continuity that Hull argues a proper conception of narrative demands. Even as particular features of the central subject might change as a narrative sequence unfolds, the narrative is still about the same historical individual.

The key to explicating the notion of a central subject is to define those features that make an historical individual one and the same individual through time, while distinguishing these features from others they may have (Hull 1975, p. 260). Chief among these central-subject-making features are continuity in space and continuity in time. By selecting individuals who are continuous in this fashion, we are in a position to say something meaningful about the historical development of a central subject relative 
to some set of events that make up its history. We can speak, for instance, of a gene as a central subject, because even as its function may change over the course of its evolutionary history, we can point to the change inducing events that would alter its function within varying environments given particular mutations. A gene can be a central subject because it is spatiotemporally continuous, and it persists under conditions of change. However, a gene for a particular trait is not an historical individual, and so does not qualify as a central subject. As Hull says, we can talk about genes as central subjects, but not genes for albinism. Once a gene for albinism has its function altered, it is no longer a gene for albinism, so considered according to its function, a gene is not an historical individual.

\subsection{Directionality}

As noted above, another key element of narrative explanations is that they rely on a sense of directionality with respect to their explanatory targets-narrative explanations depend on temporal asymmetry (Gould 1989; Beatty 2006; Gallie 1964). In Hull's case, this is partly taken care of just by giving a correct account of central subjects. Narratives are "woven around" central subjects, which is to say that the selection of the central subject, under the right conditions (involving spatial and temporal continuity), will shed light on the events that indicate the overall trajectory of the narrative sequence.

It might help to offer a concrete example. Paleobiologists are interested in investigating macroevolutionary trends in the overall history of life. The very notion of 
"trend" already indicates that there is an overall directionality to at least some of the questions paleobiologists are interested in. One such question might the evolution of body size within evolutionary lineages. Increase in the average body size of mammals since the K-T extinction, for instance, is a pretty well-established trend. Mammals (or some subset of them) can, considered as a clade or monophyletic set, fulfill the role of the central subject, as the development of mammals forms a spatiotemporally continuous series over its history. Having established a central subject, we can ask further questions, the answers to which will serve to construct a narrative, which will explicate the directionality of the historical sequence. We might, for instance, find that average body size increase is just a consequence of a random walk away from a lower bound on mammalian body size. ${ }^{14}$ If there exists a lower bound that constrains the minimal possible size for any mammal (which seems plausible) then you would expect to see some average increase just as a matter of course (Turner 2011). Or it might be that there's some selective pressure that drives adaptive radiations of animals with larger bodies, on average, than their ancestors. This need not be settled here. The point is just that once we assume the demand for directionality in narrative explanations, we see how crucial the selection of central subjects becomes. In the example above we need to tell a story about body size increase, so we know something about the general direction that the narrative will assume, but a random walk from a lower bound is likely to produce a narrative with a much different overall structure (for instance, one may have

\footnotetext{
${ }^{14}$ The statistical abstraction of average body size is not to be thought of as the central subject. It is, rather, still the mammalian clade, with the statistical abstraction working as a bookkeeping device that we might use to capture certain facts about potential narrative directions.
} 
a causal structure while the other may be non-causal) than a story involving strong selection for particular traits like size.

\subsection{Central subjects, directionality, and capacities}

Having noted the centrality of central subjects and directionality to theoretical treatments of narrative explanation, it is natural to wonder what it is about the concept of a central subject that makes it capable of occupying this integrative role within the development of an historical narrative. Hull (1975) argues that the properties that matter have mainly to do with spatial and temporal continuity. I certainly have no objection to these properties of central subjects as important, but it strikes me that this treatment of the "central subject" concept is incomplete..

Hull claims (plausibly) that organisms are paradigm examples of historical individuals. As is frequently pointed out, individual organisms change their constituent parts over their histories, but nonetheless remain the same historical individual, at least in part due to properties of spatial and temporal continuity. But it seems that these continuities aren't the only properties that matter as regards our concept of narrative explanation, and, more importantly for our current discussion, narrative possibility. Hull (1975) and Ereshefsky and Turner (2020) urge that central subjects of narratives persist under relations of change, and this fact is a key constituent of any proper conception of narrative explanation. But central to any discussion of narrative explanation is a proper notion of narrative possibility, which is the topic of our discussion here. But once we've recognized this fact, we're forced to also recognize that we need to have a theory that 
properly accounts for the ability of our central subjects to undergo change. That is, if we're committed to the claim that central subjects persist under certain change relations, we're already admitting that change is integral to our account. What we need, then, is a way to talk about central subjects that respects the demand for treating them as spatially and temporally continuous, while still being able to explicate the sense in which they can undergo change, while retaining their historical individuality.

This, I think, is where capacities do their work. What do I mean by "capacity"? Capacities are just those properties of an object that dispose it toward (or away) from some behavior (or pattern of behavior) (see Mumford 1998; Mumford and Lill Anjum 2011). To turn to a classic example, we say that salt has a disposition toward dissolving when placed in water. The question, then, is why salt is disposed to behave in such a way; the answer is that it possesses certain chemical and structural properties that enable it to discharge its disposition to dissolve-loosely bound electrons, and so on (see Strevens 2008).

We're now in a position to say some rather interesting things about central subjects and the narratives we weave around them. Let's return to the idea of genes as central subjects. Recall Hull's (1975) argument that genes may be thought of as central subjects, but "genes for albinism" cannot, since genes for albinism lack the kind of spatiotemporal continuity required for a proper conception of central subjects. This seems right as far as it goes, but it seems to leave underanalyzed the thing that was interesting about any potential narrative in the first place: how it is that the gene in question, previously functioning as a gene for $x$, changed and became a gene for albinism. 
This invites us to think not just in terms of the spatiotemporal continuity of the central subject, but also in terms of structural features inherent in that subject, which allow for it to change, while nonetheless retaining its historical individuality. In the case of the gene for albinism, we can point, perhaps, to certain facts about mutation rate, availability (or lack of availability) to selection, and its location relative to other genes as importantly influential to its capacity for change. And as regards its historical identity, we can point to ancestral genes and find that they're in fact evolutionary orthologs. This strikes me as the right way to think about central subjects. We respect the sensible demand for spatiotemporal continuity and narrative directionality, while also tackling the subject of narrative change-and in doing so, we're one step closer to a full analysis of narrative possibility.

\section{Affordances}

I said above that my approach to narrative possibility involves two key elements (perhaps in addition to some of the features of extant accounts from Hull and the like)-capacities and affordances. We have some sense of what capacities are: they're just those features of a central subject that dispose it toward (or away) from the manifestation of some state or property of interest. There's nothing especially mysterious here. We've yet to touch on the notion of an affordance with any depth or precision, however. That will be the task of this section. 


\subsection{Recalling Darwin's PD}

In my earlier (somewhat loose) remarks on my ecological approach to narrative possibility, I mentioned Darwin's PD as a useful motivating example for what this conception of possibility can accomplish. Darwin thought that the explanatory target of his principle was the rich diversity of life on Earth, and in order to fully explain it, it is necessary to have a robustly ecological view of the processes that drive diversification (Kohn 2009; Worster 1994).

By explicating the notion of something's (e.g. an organism) having a capacity, we've really only explicated half of the concept of what it means for some narrative pathway to be "possible" for it. Darwin's PD invites us to realize why this is the case. In the PD it is not just the features of the organism that provide the explanation for the diversification of lifeforms; rather, it is in part because nature is structured in a certain way that creatures can diversify at all (Pence and Swaim 2018).

It might help to think about things in somewhat more concrete terms. Let's assume that some species, $S$, is under a selective regime, and that the selective regime in question is inducing anagenic speciation over some subpopulation, $S^{*}$, of the species. According to PD, this new species, $S^{*}$ (or "incipient species," etc.) is made better off by an ability to diversify further away (morphologically) from its ancestor, as a less diversified variant will face too much competition from its parent population. But this can only be made sense of in terms of some background structural features of the "Economy" or "Polity" of nature. In order to properly understand what is happening, it is necessary to see that what is possible for an organism or a population is only fully 
accounted for once we see that the relation of interest is a relation between the features that organisms have, and the background structure in which they're embedded. The natural world has a structure, and what is possible in terms of evolutionary pathways (i.e. narratives) is to be made sense of in terms of relations that hold between the properties of biological systems (capacities) and the environmental backdrop (affordances). Importantly, the state of this relation, for any given central subject, is not fixed. Indeed, this is what makes things so interesting.

It may be that in some ancestral state of a population, the set of possible evolutionary outcomes consists of some set $\{\mathrm{E} 1, \mathrm{E} 2, \mathrm{E} 3\}$. In any realistic case the possibilities are going to be much more numerous, but this will suffice for a toy example. Now suppose that a mutant variant for some gene controlling body segmentation (or whatever) spreads through the population, constricting the set of possible body types that are evolvable for the population in its current ecological context. Given a few generations of reproductive output, we can say, perhaps, that E1 is ruled out as a biological possibility. But the others remain, and it may be that the situation is such that some new pathway, E4 becomes possible for our toy population. The point is just that the situation is fluid, and tracking the state of the relation between the capacities of the central subject and the features of its environment are central to the concept of narrative possibility being advanced.

In Darwin's (1859) words, PD tracks the ability of organisms and populations to "seize upon" one or some of the many places in the "polity of nature." We're no longer inclined to speak in precisely this sort of language, but the imagery nonetheless latches 
onto something important - that the world has a structure which can be exploited; that there is something to be seized upon in the first place. Which parts of the structure of nature will be exploitable depends in part on just what capacities our central subjects have, and this is, according to the ecological view, the nature of narrative possibility.

\section{Putting things together}

At this point it seems like a good idea to put together some synthetic remarks on the ecological account, and to recapitulate some of the key points of the paper so far. Having done that, we'll be in good position to discuss some potential objections to the account in the next section.

\subsection{A brief restatement of the account}

The ecological account introduces two key concepts to the conversation over the nature of narrative possibility: capacities and affordances. Hull (1975), Gallie (1964), and Ereshefsky and Turner (2020) stress the importance of central subjects and directionality for any account of narrative explanation. Given that narrative possibility features as a component of our theory of narrative explanation, it seems sensible to take central subjects and directionality as important elements of our treatment of narrative possibility.

What we find is that the introduction of these notions of "capacity" and "affordance" allows us to say some interesting things about narrative possibility. We can track possibility as a relation between the capacities of central subjects and their 
ecological context (broadly construed). For some outcome or pathway to be narratively possible, we just mean that that outcome or pathway is consistent with the relevant properties of our central subjects and their environment. The nature of this relation is liable to change over time-what is possible for some central narrative subject at some earlier time may not be possible at some later time, and vise versa. The properties of central subjects may change, as might their environment, and so certain narrative possibilities may be opened up or foreclosed upon as a narrative sequence progresses (see Beatty 2017).

\subsection{Back to initial comments on motivation}

In an earlier part of this paper, I motivated my account by situating it within a broader debate between what I called metaphysical and epistemological approaches to narrative possibility. The metaphysical approach takes possibility to be a real part of the world's structure. An important part of the function of narrative explanation, on this account, is to make sense of the structure of possibility. On the epistemological account, our concept of possibility is just a consequence of our knowledge situation. Possibility simply relates to, for instance, evidential underdetermination. Narrative explanation, then, can be properly motivated independently of metaphysical questions concerning the structure of possibility in the world. With the ecological position on the table, we're now in a position to elaborate on these points a bit.

As already noted, I think metaphysical conception and the epistemological one latch onto some important points. The metaphysical theorist is right to think that our 
concept of possibility should treat it as something that's baked into the structure of the world, while the epistemological theorist is right to resist metaphysical overextension. The question, then, is how to thread the needle appropriately.

The ecological approach threads the needle by providing an account that jettisons the most metaphysically controversial bits of the more robustly metaphysical approach, while being less metaphysically deflationary than the epistemological approach. The most controversial aspects of the metaphysical approach were its seeming commitment to the reality of unrealized historical branches, and causal indeterminism. The ecological approach involves no such commitments. On the ecological approach, we track a relation between the properties of central subjects and the environment in this world. All of the facts concerning what is possible are merely facts that can (at least in principle) be read off of the actual history of the central subject. There is some real sense in which "alternate histories" or "potential alternate histories" exist on the ecological account, but this is because there are several histories that are consistent with the relation being tracked by the account.

So, by locating our concept of narrative possibility in a this-worldly relation between the capacities of central subjects and the affordances provided by their environment (or context, etc.), we can retain some of the best insights from each of the aforementioned approaches. "Possibility" is not banished from the world or relegated to our evidential situation, but we also do not have to commit to metaphysically controversial ideas like causal indeterminism or the "reality" of unrealized causal histories. 
One might think, however, that I've simply traded in one set of metaphysically dubious claims for another. While we may not have to talk about "unrealized causal histories" and the like, we are now committed to the existence of capacities and affordances, and these may not be metaphysically innocent notions. I'll look at this problem in a later section, as I turn my attention to some potential objections, and my replies to them.

\section{Narrative possibility and explanatory modal spaces}

I made a promise that I've yet to follow through on. I said that a major benefit of the ecological conception of narrative possibility is that it appropriately delimits the modal spaces that our explanatory tasks are understood to cover. Moreover, it does so in ways that the metaphysical and epistemological approaches fail to do.

In the next section I'll have some more comments on the salience of context, but some comments on the importance of context to explanatory tasks also bear mentioning here. There are several senses in which we might say that explanatory tasks are relative to a certain context. It may be that the kind of explanation given is sensitive to the kind of question asked (e.g. Garfinkel 1981), or the explanatory aims or investigators (e.g. Giere 1999), or because of the kinds of practices that make up the specific discipline an investigator inhabits (e.g. Potochnik 2017). Whether any of these specific conceptions of context sensitivity is right or wrong is not a point at discussion here-it seems clear, however, that it must be right that explanatory tasks are in some sense sensitive to context. 
A major theme in the literature on scientific explanation are debates centered around epistemic as opposed to ontic accounts of explanation (see Salmon 1984). This debate is well-worn enough that it need not be recapitulated here. It isn't too much of a stretch to say that, as regards narrative explanations in particular, the metaphysical approach to narrative possibility will likely be tied to ontic narrative explanations, and the epistemological approach tied to epistemic theories of narrative explanation. The problem, as I see it, is that narrative explanations, depending on context, will exemplify a tendency to vary between ontic and epistemic explanatory concerns.

Consider two kinds of cases that seem apt for narratization: the evolutionary emergence of a novel trait, and a significant decision made by some important historical actor. Popular examples of the former are things like the evolution of novel metabolic abilities in laboratory evolution experiments (see Parke 2014), and the latter might include Julius Caesar's crossing of the Rubicon. In the former (biological) context, we want a conception of possibilities that maps onto the causal structure of the world. That is, the thing we're trying to explain, via narrative, is something that is clearly well within the causal web of the world, and so the space of possibilities should be tracking that structure in (at least approximately) the right way. In the latter (human historical) context, it is at least less precisely the case that what we're dealing with is straightforwardly a part of the world's causal web. As many philosophers of history (Roth 2020; Mink 1987; Goldstein 1996) have noted, historical explanation (here in the sense of explaining events in human history) involves a great deal of cognitive 
projection. ${ }^{15}$ The exact sense in which this is the case will vary from author to author, but in general, the claim is that for certain kinds of narrative explanatory tasks, the explanations are very much objects of human construction. This may be the case for a number of disciplines besides history-sociology, psychology, and anthropology might have similar explanatory practices (see Chapman and Wylie 2016, Ch. 1 for instance). While I don't go in for a fully constructivist account of explanation for any empirical discipline, (as, for instance, Roth $(2019 ; 2017)$ seems to do with history), it does seem plausible that there might be constructive components to historical or anthropological explanation that aren't present in evolutionary explanation. This is because these disciplines must deal with facts about mentality in addition to materiality (Chapman and Wylie 2016).

The metaphysical approach to narrative possibility is not going to be well-suited to the task of delimiting modal spaces where epistemic explanatory concerns are emphasized. The metaphysical approach, at base, is attempting to carve nature at its modal joints. When you take the metaphysical knife to the structure of the world, you are attempting to carve out the physical possibilities for your central subject given its relevant context; you are, in effect, looking for the set of possible state spaces for the subject (see Strevens 2008, p. 266). But there's no such way to carve in epistemic contexts, as the traces of, for instance, mentality that feature in such explanations have no apparently (fully) objective carving.

\footnotetext{
${ }^{15}$ This idea has taken many forms. R.G. Collingwood (1946) talks about it in terms of "inhabiting" the mental spaces of historical agents. Mink (1987) talks about narratives as "cognitive instruments." For an argument against this kind of function for narrative, the reader may want to look at Rosenberg (2018). His argument there hinges on the unreliability of "theory of mind" for explanatory purposes. It merits mentioning, however, that he does not directly engage any of the existing scholarship on narrative explanation.
} 
The epistemological approach seems to fail to delimit the modal space of possibilities appropriately when applied to explanatory concerns of a more ontic flavor. The epistemological approach is concerned primarily with delimiting possibility as a space of possible narrative trajectories that are compatible with our knowledge situation. This, it seems, does not fit well with a great deal of scientific practice, wherein the point is to lay bare (to the extent possible) what the structure of physical possibilities is really like, and subsequently, why things turned out to be the way they are. Think, for instance, of Conrad Waddington's (1957) "landscape" depiction of mammalian development. The idea to be captured is that developmental patterns can be more or less entrenched or "canalized," which is supposed to be informative of the degree to which particular developmental pathways are physically realizable (which, of course, depends on facts about organismal types and environmental influences). Thinking about the modal space over which explanations range in this context involves thinking about the world's underlying structure and how it affords for some possibilities and not others. The epistemological approach falls short here.

The ecological approach, however, allows for a degree of flexibility when shifting between ontic and epistemic explanatory modes. ${ }^{16}$ This is due to the emphasis on central subjects and their capacities as they relate to narrative modes of explanation. In the ontic direction, the compatibility with the ecological approach is clear: with knowledge of the relevant capacities of the central subject (mammals, bacteria,

\footnotetext{
${ }^{16}$ I want to signal here that my sympathy is with the ontic approach to explanation. Much of the recent literature on explanation (narrative or otherwise) has been shifting in the epistemic direction (see Bokulich 2016, for instance). Some explanatory tasks may have more of an epistemic flavor, but in any empirical discipline, the explainers, in my view, are always things in the world.
} 
geological formations, etc.) and a specification of background or contextual factors, the modal space is effectively fixed. It is just the set of causal sequences that are possible given the structural features that make up the capacities of the central subject and its concomitant environmental context.

Roughly the same is true with respect to epistemic explanatory contexts. Here we said that explanation involves some degree of projection. ${ }^{17}$ This can take several forms: construction, speculation, perhaps some manner of idealization, or what have you. Even in the most epistemically laden context (think literary theories of narrative explanation, for instance), there are narrative subjects outfitted with capacities (psychological predispositions, for instance) that drive narratives, but always in a way that's constrained by context. Dmitri Karamazov is driven to the brink of murder not only because he's passionate, but because his passion involves a particular person of interest (Grushenka), whom his father beds. The ecological conception allows us to shift our conception of possibility between epistemic and ontic modes of narrative explanation as needed, and in either case, we delimit the modal space in the right way. The same is not true for other accounts.

\section{Objections and replies}

I'll now explore some objections to my account, and do my best to respond to them. There are two potential objections that I'd like to address. I've already mentioned

\footnotetext{
${ }^{17}$ I think this must be true even in the case of Ereshefsky and Turner (2020) and the like, even though the make no proclamations to that effect (as does Roth (2019), for instance). If your view is that explanation must proceed in the face of widespread local underdetermination, it seems it must be the case that some of the structure of the narrative and its modal space is projected.
} 
the first. This is the claim that my account is not as metaphysically innocent as I've suggested, since although it doesn't command our assent to causal indeterminism and the like, it does introduce the notions of capacities and affordances. The second objection we might call the "Pluralist's Objection." The pluralist may argue that there's no reason to think there was ever a problem to solve: we can be epistemological theorists when it suits us, and we can switch hats and be metaphysical theorists in other contexts.

\subsection{Metaphysics and the ecological account}

The objection here is that the ecological account is not really as metaphysically innocent as I've made it out to be. The objectionable parts of the metaphysical theorist's account (as in Beatty 2016; 2017) have to do with its commitment to things like the reality of unrealized causal histories and causal indeterminism (Ereshefsky and Turner 2020). But in removing our commitment to these notions, we've introduced new metaphysical concepts like "capacities" and "affordances." What should we make of this?

It strikes me that not all metaphysical concepts are necessarily on par with respect to a "scientific" or "naturalist" outlook. What do I mean by this? Well, it seems sensible enough to say that our metaphysical commitments should be significantly constrained by science. Ideally, our ontological or metaphysical outlook should not just be constrained, but significantly informed by our scientific outlook (Chakravartty 2017). One way of testing the naturalistic or scientific credentials of our metaphysical 
commitments is to assess the degree to which they're empirically tractable. Call this the Naturalist Criterion of Tractability (NCT). A metaphysical commitment satisfies NCT when that commitment makes some difference to the success of some set of scientific practices (broadly construed). ${ }^{18}$

So, while it may be true that the capacities and affordances are not metaphysically innocent or neutral, I do think they satisfy NCT. I've already gestured at this in the previous discussion of Darwin's PD. In developing his thinking around PD, Darwin was not engaging in a priori speculation on the structure of nature in relation to his theory of evolution by natural selection. Darwin sought empirical justification for his treatment of the nature of diversification processes. He argues that the "truth of the principle is seen under many natural circumstances" (Darwin 1859, p. 114). He cites the properties that contribute to patterns of diversification: geographical area, rates of immigration, level of interspecies competition for resources, etc. So committing to the reality of capacities and affordances is driven by the evidence available to him through the observation of natural processes. The use of these concepts gave Darwin at least some of the necessary tools for finding successful explanations of certain evolutionary patterns, thereby satisfying NCT. In the words of Nancy Cartwright (2015), nature "wears its capacities on its sleeve." The same might be said for affordances, which are, in some sense, the flip-side of capacities. So, while these notions may not be entirely metaphysically neutral, they seem to pass muster from a naturalistic perspective.

\footnotetext{
${ }^{18}$ For instance, inference methods, explanations, observation techniques, model building, mathematical representation, etc. may all fall under the umbrella concept of "practices."
} 
One would be hard-pressed to make similar claims for causal indeterminism or realism about unrealized causal histories. Unrealized causal histories seem to me entirely inaccessible to observation, and causal indeterminism only in very indirect ways. Those arguing for the reality of unrealized history tend to lean heavily on speculative remarks concerning the apparently high degree of contingency in certain kinds of natural processes (e.g. evolutionary history). This is the tactic of, for instance, Gould (1989) and Beatty (2006) when they discuss the "tape rewinding" thought experiment. The experiment is simple: play forward the tape of life from beginning to end to get a full picture of the course of evolution on Earth. Then, choose any point in that history you like, rewind to the moment just before, and play forward again. The speculative question, then, is, "Would the history of life look the same on the next play?" Gould and Beatty say no; there's just too much inherent contingency in evolutionary processes. Two plays of the tape will never be alike, even from the same initial conditions.

We need to tease apart a few issues here. Considered with respect to NCT, certain kinds of unrealized possibilities will turn out to be naturalistically satisfactory, while others will not. The kinds of causal inferences defended on counterfactual and manipulationist accounts of causal explanation and inference (e.g. Woodward 2003) appeal to unrealized possibilities of a certain kind: possibilities that fail to be realized due to an intervention on a system. In cases such as this, we do get some empirical evidence about non-actual states of affairs, and it certainly counts as information that makes a difference to scientific practice. But it is important to note that these kinds of 
methods are silent with respect to the ontological status of unrealized or non-actualized possibilities. With an intervention in place, the Woodwardian would not proceed to make claims about whether the prevented state is a part of the world and that we should take this or that ontological stance toward it; rather she would simply claim some modal information concerning what the difference makers for the system are. Philosophers like Beatty (2017) make a further, rather drastic step. They claim that unactualized possibilities (or alternate histories, etc.) have some claim over our ontological commitments: we should say that they exist (what, exactly, this means is not well explained by Beatty, Gould, or any other such theorist). This, I claim, fails to satisfy NCT, and so should not be a part of our proper conception of narrative possibility.

The commitment to causal indeterminism is perhaps a bit more sensitive to empirical evidence, but only in a rather indirect sense. It is sometimes argued, for instance, that the best way to interpret random or stochastic processes in nature is to take them at face value (see Lowe 2008; DesAutels 2015). This is to say that if natural processes appear indeterministic, then we should assume that they are, unless and until we have evidence to the contrary.

This claim seems ok at the level of methodology, but bizarre as a matter of metaphysical commitment. To commit to indeterminism on the basis of seemingly stochastic or chancy natural processes seems to require one to say that causal indeterminism is the only explanation for the appearance of such processes. But this seems like a stretch. Much is made, for instance, of quantum indeterminacy (see again Lowe 2008) as regards causal indeterminism, but many interpretations of quantum 
processes are on the table: Everettian interpretations, explicit theories of wave-function collapse, and Bohmian interpretations, to name a few. All of these are compatible with determinism even where the world appears phenomenologically indeterministic. And besides, we seem to have plenty of empirical justification for determinism at the level of classical physics and relativistic physics, etc. This is all enough to show that we don't want our account of narrative possibility to force our hand on such a metaphysically contentious issue. Considered against NCT, it seems like agnosticism is the best position with respect to determinism and indeterminism. We can, in practice, do just as well in either case.

\subsection{Pluralism and the ecological account}

Now we'll consider the following worry: might it be that we should just be pluralists concerning the nature of narrative possibility? In some contexts, it might be the case that the epistemological approach is the one best suited to our explanatory tasks, and in other cases it will be appropriate to take an metaphysical stance. So, rather than providing an overarching account of narrative possibility for our theory of narrative explanation, we should let contextual factors dictate which approach serves us best (similarly to Garfinkel 1981).

I think this objection tracks an important concern: science is not epistemologically or methodologically homogenous (Currie 2018; Potochnik 2017; Weisberg 2013). Scientists use different tools and explanatory strategies that reflect their different evidential situations, disciplinary matrices, and track records of 
methodological success. Given that this is so, we don't want to judge too much in advance as concerns what kinds of philosophical accounts of science and scientific practice should be taken as properly applicable. Philosophy of science is important, but it should be philosophy of actual science, and actual science is quite diverse (along many axes of evaluation).

I agree with the above concern, but I would add that insofar as a domain of scientific inquiry is able to support a heterogeneous array of methodologies, explanatory strategies, and the like, we still want to know why that's the case. It's not very satisfying to leave the heterogeneity of scientific practices as an unanalyzed brute fact. I think the ecological account of narrative possibility provides some insight here.

Even in domains where pluralism reigns supreme, the success of pluralism (methodological, explanatory, or otherwise) must be supported by some fact about the world (or so I shall claim). In our own case, the structural facts concerning the nature of narrative possibility show why both epistemological-seeming and metaphysical-seeming strategies can find success. I've argued that the way to think about narrative possibility is as a complex structure of relations holding between the capacities of central subjects and their context or environment. From the perspective of the metaphysical theorist, we're trying to answer something like the question, "Why, among all the possible histories, is this the one that was actualized?" In the words of Beatty (2017) we want to know how possible histories are "foreclosed upon." From the perspective of the epistemological theorist, the question is something like, "Given the limited evidence at my disposal, why should I think that this historical reconstruction is 
explanatorily adequate, compared to competitors?" The ecological account can accommodate both sorts of questions. From a metaphysical slant, historical reconstructions aim to answer the question by showing how the actual causal history of the central subject developed and closed off other possibilities. This is a matter of tracing the development of the central subject and the development of its capacity-affordance relation over time. From an epistemological slant, we're more interested in understanding how our limited evidence can support some set of historical reconstructions. With respect to the epistemological question, we go about the task of answering it by finding how the evidence can fit into our picture of the world. We try, in some sense, to generate the space of possibilities by finding all the ways (or all the plausible ways) in which our evidence fits with what we know about the world. This plays quite nicely with the idea of capacities and affordances I've been advancing in this paper.

Which sort of question scientists will ask is a matter of context, but the ecological account answers the underlying question of why it is that pluralism and context sensitivity prevail as regards methodological and explanatory success. The answer is, unsurprisingly, a metaphysical one; that is, it is because the world is structured in a way that supports a plurality of approaches.

\section{Concluding remarks}

In this paper I've argued for a new way of understanding the role and structure of possibility in narrative explanation. I call this account of narrative possibility 
ecological, because it draws our attention to the ways in which central subjects relate to their environment or context-a relation between capacities and affordances. We explored other approaches that I called metaphysical and epistemological, respectively. The advantage of the ecological account is that it respects the metaphysical theorist's insight that possibility is baked into the world's structure, but resists the metaphysical overextension that epistemological theorists warn is looming over such accounts. Moreover, the ecological account delimits the modal space of narrative explanatory tasks in the right way, which we saw by situating it within types of explanatory tasks, ontic and epistemic. The result is an account with much conceptual flexibility, but which casts some light on the conceptual machinery of narrative explanation and how it works. 


\section{Citations}

Beatty, John. 1993. “The Evolutionary Contingency Thesis," in Concepts, Theories, and Rationality in the Biological Sciences, Wolters and Lennox (eds.). Pittsburgh: University of Pittsburgh Press.

Beatty, John. 2006. “Replaying Life's Tape," in Journal of Philosophy 53: pp. 45-82.

Beatty, John. 2016. “What Are Narratives Good For?" in Studies in History and Philosophy of Biological and Biomedical Sciences 58: pp. 33-40.

Beatty, John. 2017. “Narrative Possibility and Narrative Explanation," in Studies in History and Philosophy of Science 62: pp. 31-41.

Beatty, John and Desjardins, Eric. 2009. "Natural Selection and History," in Biology and Philosophy 24: pp. 231-246.

Bochulik, Alisa. 2016. “Fiction as a Vehicle for Truth: Moving Beyond the Ontic Conception," in The Monist 99 (3): pp. 260-279.

Cartwright, Nancy. 2015. "Contingency and the Order of Nature," in Studies in the History and Philosophy of Biological and Biomedical Sciences.

Chapman, Robert and Wylie, Alison. 2016. Evidential Reasoning in Archaeology. New York: Bloomsbury.

Chakravartty, Anjan. 2017. Scientific Ontology: Integrating Naturalized Metaphysics and Voluntarist Epistemology. Oxford: Oxford University Press.

Cleland, Carol. 2011. "Prediction and Explanation in Historical Natural Science," in British Journal for the Philosophy of Science 62 (3): pp. 551-582.

Collingwood, R.G. 1946. The Idea of History. Oxford: Oxford University Press. 
Currie, Adrian. 2018. Rock, Bone, and Ruin: An Optimist's Guide to the Historical Sciences. Cambridge, MA: The MIT Press.

Currie, Adrian. Manuscript. History Matters: Knowledge $\mathcal{E}$ the Deep Past.

Currie, Adrian. 2018. Rock, Bone, and Ruin: An Optimist's Guide to the Historical Sciences. Cambridge, MA: The MIT Press.

Currie, Adrian. 2019. History Matters: Knowledge \& the Deep Past. Cambridge: Cambridge University Press.

DesAutels, Lane. 2015. “Toward a Propensity Interpretation of Stochastic Mechanism for the Life Sciences," in Synthese 192: pp. 2921-2953.

Desjardins, Eric. 2011. "Historicity and Experimental Evolution," in Biology and Philosophy 27: pp. 381-400.

Dray, William. 1959. "Explaining 'What' in History," in Theories of History (Gardiner ed.). New York: The Free Press.

Ereshefsky, Marc and Turner, Derek. 2020. "Historicity and Explanation," in Studies in History and Philosophy of Science 80: pp. 47-55.

Gallie, W.B. 1955. “Explanations in History and the Genetic Sciences,” in Mind 64: pp. $160-180$.

Gallie, W.B. 1964. Philosophy and the Historical Understanding. Belfast: Queen's Press.

Garfinkel, Alan. 1981. Forms of Explanation. New Haven: Yale Press.

Goldstein, Leon. 1996. The What and the Why of History. New York: Brill.

Hempel, Carl G. 1942. "The Function of General Laws in History," in Journal of Philosophy 39 (2): pp. 35-48. 
Hempel, Carl G. and Oppenheim, Paul. 1948. "Studies on the Logic of Explanation," in Philosophy of Science 15 (2): pp. 135-175.

Hull, David. 1975. "Central Subjects and Historical Narratives." History and Theory 14 (3): 253-74.

Giere, Ronald. 1999. Science Without Laws. Chicago: Chicago University Press.

Gould, Stephen J. 1989. Wonderful Life: The Burgess Shale and the Nature of History. New York: Norton.

Kohn, David. 2009. “Darwin's Keystone: The Principle of Divergence," in The Cambridge Companion to "Origin of Species," Ruse and Richards (eds.). Cambridge: Cambridge University Press

Lowe, E.J. 2008. Personal Agency: The Metaphysics of Mind and Action. Oxford: Oxford University Press.

Mayr, Ernst. 1982. The Growth of Biological Thought: Diversity, Evolution, and Inheritance: Cambridge: The Belknap Press.

Millstein, Roberta. 2000. "Chance and Macroevolution" in Philosophy of Science 67 (4): pp. 603-624.

Mink, Louis O. 1970. "History and Fiction as Modes of Comprehension," in New Literary History 1: pp. 541-558.

Mink, Louis O. 1978. "Narrative Form as a Cognitive Instrument," in The Writing of History: Literary Form and Historical Understanding (Canary and Kozicki eds.). Madison: University of Wisconsin Press.

Mumford, Stephen. 1998. Dispositions. Oxford University Press. 
Mumford, Stephen and Lill Anjum, Rani. 2011. Getting Causes from Powers. Oxford: Oxford University press.

Parke, Emily. 2014. "Experiments, Simulations, and Epistemic Privilege," in Philosophy of Science 81 (4): pp. 516-536.

Pence, Charles H. and Swaim, Daniel G. 2018. “The Economy of Nature: The Structure of Evolution in Linnaeus, Darwin, and the Modern Synthesis," in European Journal of Philosophy of Science 8 (3): pp. 435-454.

Potochnik, Angela. 2017. Idealization and the Aims of Science. Chicago: Chicago University Press.

Roth, Paul A. 2017. “Essentially Narrative Explanations.” Studies in History and Philosophy of Science Part A. Elsevier Ltd, 1-9. doi:10.1016/j.shpsa.2017.03.008.

Roth, Paul A. 2020. The Philosophical Structure of Historical Explanation. Evanston: Northwestern University Press.

Salmon, Wesley. 1984. Scientific Explanation and the Causal Structure of the World. Princeton: Princeton University Press.

Salmon, Wesley. 1989. Four Decades of Scientific Explanation. Princeton: Princeton University Press.

Strevens, Michael. 2008. Depth: An Account of Scientific Explanation. Cambridge, MA: Harvard Press.

Swaim, Daniel G. 2019. “The Roles of Possibility and Mechanism in Narrative Explanation," in Philosophy of Science 86 (5): pp. 858-868. 
Turner, Derek. 2007. Making Prehistory: Historical Science and the Scientific Realism Debate. Cambridge: Cambridge University Press.

Turner, Derek. 2011. Paleontology: A Philosophical Introduction. Cambridge: Cambridge University Press.

Waddington, Conrad. 1957. The Strategy of the Genes. New York: Routledge

Weisberg, Michael. 2013. Simulation and Similarity: Using Models to Understand the World. Oxford: Oxford University Press.

Woodward, James. 2003. Making Things Happen: A Theory of Causal Explanation. Oxford: Oxford University Press. 